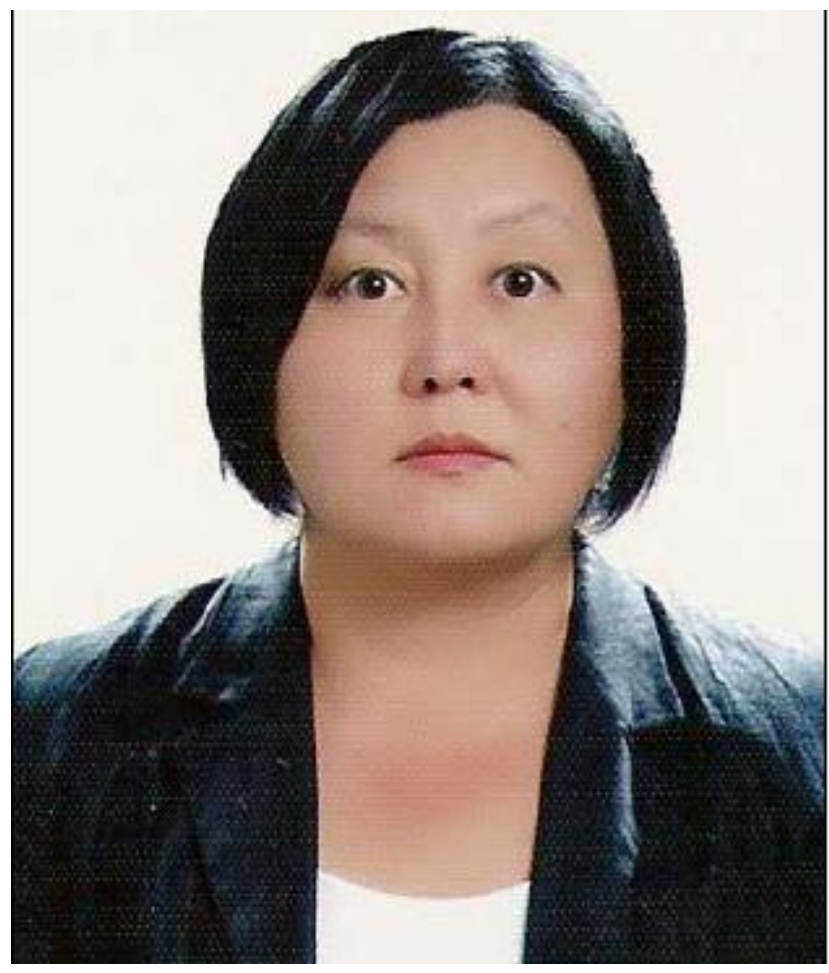

\title{
On sweet undeniable feeling of power of international intellectual feudalism, bias, discrimination, censoring, theft, and yet cloud of rumors again - Part 1
}

\author{
Gulmira Kudaiberdieva \\ Editor-in-Chief \\ Heart Vessels and Transplantation
}

This is a first piece we open for debate and discussion. As every editor can comprehend from the title of this short introduction, this is about may be some journal editors have experienced or it may only be intrinsic for our journal. Why we decided to write this short article? As I noted in the editorial of the $2^{\text {nd }}$ issue, we still trying to find clues for the dilemma - access worldwide and low rate of any unsolicited submissions. Below there are few points I have tried to address, and any other type of infringement and blocking site and damaging editorial independence which comes outside of the origin of the journal $s$ country or its team - owner/ publisher or industry support they receive declared support for editorial independence, I define as " intellectual feudalism " meaning that some countries try to own the journal and assign groups (even religious - some wealthy publishers that can shake thrones of editors independence, fire them or acquire for sky-rocket high prices independent journals and editorial boards and editors without their knowledge, like lambs on farm markets), publishers, journals, academic institutions to monitor, supervise (big country or small country issue, developed or underdeveloped country issue) and control content, stealing intellectual property and committing theft; this kind of things fell in medieval rule, that still exist in some regions and countries. 
Why I have decided to write this piece, for simple reason, to explain why the same insinuations continue popping up like it was 15 years ago with my another experience as editor, are the same forces in place for biomedical publishing? We have reached accesses from 325 cities across all continents, our articles though due to latest survey of our editors, reviewers and authors are still desirable to be of high-quality, nevertheless articles are read and downloaded. There was a speculation 15 years ago, that if someone would visit website and download multiple times their article that would count statistics. But it is not true for our journal, as we have no any relations with those who downloads and our statistics can show the downloads that performed with malicious disgraceful purpose and we actually can track back to the origin and source of this (ip, browser and device), but we do not do this, because we are scientists and it is actually is the function of law enforcement, and if we apply with complain and they can investigate.

To define "intellectual feudalism", we need to provide definition of feudalism - the social system that existed during Middle Ages where people received a piece of land and protection from nobleman and in return worked and fought for him (Hornby, AS, Crowther J. Oxford: advanced learners dictionary of current English. $5^{\text {th }}$ ed. Oxford University Press; 1995.). Therefore, intellectual feudalism can be defined as some noble powers pretend permitting publishing journal and in return, they are trying to affect the desire of authors to share their power of reasoning and knowledge and willingness of reviewers and ability of editors to assess this knowledge and make it public through unbiased peer-review process. Also that is being felt, that some countries or organizations or individuals unjustifiably almost on criminal level act like noble feudal trying to impose their beliefs, thoughts and policies, by hacking and damaging journal's infrastructure, theft with re-routing any intellectual property to their own media, affecting decisions of reviewers to accept invitations, editors by any means- material or career advancement support, simply hacking website and emails contact lists to deploy unfair rules of nasty game. I can only explain it in one word of jealousy, and trying to own and demonstrate everyone that we are not capable of running an international biomedical journal, without "nobleman or noble country" censoring.

Competition is inherent to stimulate any advancement of thought or science, which is the evidencebased medicine, it is as the free market of science, but the feudal rules fall in frame of industrial spying and crime, and we cannot move further with this and we fight for our independence as biomedical multidisciplinary international journal. I always stand for the free market rules in journals ' performance. Impact factors (IF) or any other metrics, but IF is the most important as it shapes the career advancement of researchers in many countries, should be given to every journal applying to databases then it will be the real "free market' rule like in economics, every journal that cannot perform better they will just receive lowest metrics and will be off the competitive environment of free market of scientific thought (bankruptcy) until they improve performance. It means I stand for freedoms and not a single country or publisher, journal, university or anyone can apply their self-assigned regulation feudal rules of theft that simply will cause legal actions.

Of note, the journal exercises and embraced all international policies and rules set by ICMJE, WAME, COPE, etc., and declared it in the Aims and Scope and website, we as the editors carry responsibility for content of the published articles that will conform the security measures that every international editorial guideline relies on and we apply policies to avoid fabrication and plagiarism as well. Beyond that, every single infringement by any country is accepted as self-assigned intellectual feudalism.

To be continued. 